\title{
The acute respiratory distress syndrome
}

\author{
Christopher Wood, DO ${ }^{\mathrm{a}}$ (D), Vivek Kataria, PharmD ${ }^{\mathrm{b}}$ (D), and Ariel M. Modrykamien, MD \\ ${ }^{a}$ Division of Pulmonary and Critical Care Medicine, Department of Internal Medicine, Baylor University Medical Center, Dallas, Texas; \\ bepartment of Pharmacy, Baylor University Medical Center, Dallas, Texas
}

\begin{abstract}
Acute respiratory distress syndrome (ARDS) is a prevalent cause of acute respiratory failure with high rates of mortality, as well as short- and long-term complications, such as physical and cognitive impairment. Therefore, early recognition of this syndrome and application of well-demonstrated therapeutic interventions are essential to change the natural course of this entity and bring about positive clinical outcomes. In this article, we review updated concepts in ARDS. Specifically, we discuss the current definition of ARDS, its risk factors, and the evidence supporting ventilation management, adjunctive therapies, and interventions required in refractory hypoxemia.
\end{abstract}

KEYWORDS Acute respiratory distress syndrome; hypoxia; mechanical ventilation; respiratory failure

\section{CME}

Target audience: All physicians

Learning objectives: After reading the article,

the learner should be able to

1. Describe causes and risk factors of acute respiratory distress syndrome (ARDS) and conduct a differential diagnosis of ARDS in symptomatic patients.

2. Describe the evidence-based treatments for ARDS and apply the mechanistic role of these treatment strategies in ARDS.

Faculty credentials/disclosure: Dr. Christopher Wood is chief fellow in pulmonary and critical care medicine, Dr. Vivek Kataria is a board-certified critical care pharmacy specialist, and Dr. Ariel Modrykamien is chief of the medical intensive care unit at Baylor University Medical Center at Dallas. The planner and authors have no conflicts of interest.

Accreditation: The A. Webb Roberts Center for Continuing Medical Education of Baylor Scott \& White Health is accredited by the Accreditation Council for Continuing Medical Education to provide continuing medical education for physicians.

Designation: The A. Webb Roberts Center for Continuing Medical Education of Baylor Scott \& White Health designates this journal CME activity for a maximum of 1.0 AMA PRA Category 1 Credit $^{\mathrm{TM}}$. Physicians should claim only the credit commensurate with the extent of their participation in the activity.
ABIM MOC: Successful completion of this CME activity, which includes participation in the evaluation component, enables the participant to earn up to 1.0 Medical Knowledge points in the American Board of Medicine's (ABIM) Maintenance of Certification (MOC) program. The CME activity provider will submit participant completion information to ACCME for the purpose of granting ABIM MOC credit.

Process: To complete this CME activity, read the entire article and then go to https://ce.bswhealth.com/ Proceedings2020. You will register for the course, pay any relevant fee, take the quiz, complete the evaluation, and claim your CME credit. For more information about CME credit, email ce@bswhealth.org.

Expiration date: July 1, 2022.

$\mathrm{n}$ the late 1960s, based on a group of patients that presented with acute-onset hypoxemia, poor lung compliance, and tachypnea, a clinical entity was described and termed adult respiratory distress syndrome. ${ }^{1}$ Later, after similar clinical cases were reported across all age groups, the condition's name was changed to acute respiratory distress syndrome (ARDS). In the United States, a population-based study estimated the incidence of ARDS as 190,000 cases per year. ${ }^{2}$ Additionally, mortality in ARDS remains unacceptably high. An international multicenter study showed a mortality

Corresponding author: Ariel M. Modrykamien, MD, Medical Intensive Care Unit, Baylor University Medical Center, 3500 Gaston Ave., Suite H208, Dallas, TX 75246 (e-mail: Ariel.Modrykamien@BSWHealth.org)

Received January 6, 2020; Revised March 27, 2020; Accepted April 6, 2020. 
Table 1. Common risk factors for acute respiratory distress syndrome/acute lung injury

\begin{tabular}{ll}
\hline Direct & \multicolumn{1}{c}{ Indirect } \\
\hline - Pneumonia & - Nonpulmonary sepsis \\
- Aspiration of gastric contents & - Major trauma \\
- Inhalation injury & - Pancreatitis \\
- Pulmonary contusion & - Severe burns \\
- Pulmonary vasculitis & - Noncardiogenic shock \\
- Drowning & - Multiple transfusions (>15 units \\
- Fat embolism & of blood in 24 h) or \\
- Reperfusion pulmonary & transfusion-related \\
edema after lung & acute lung injury \\
$\quad$ transplantation & - Neurogenic pulmonary edema \\
$\quad$ or pulmonary embolectomy & - Following bone marrow \\
& transplantation \\
& \\
\hline
\end{tabular}

rate of $40 \%$ across patients who met ARDS criteria. ${ }^{3}$ Due to the importance of this clinical condition, this article reviews updated therapeutic interventions for patients with ARDS.

\section{DEFINITIONS AND DIAGNOSIS}

ARDS is a rapid onset of respiratory failure caused by direct and/or indirect lung insults. Since originally described, this condition has had multiple definitions and proposed diagnostic criteria. In 2011, the European Society of Intensive Care Medicine proposed the Berlin ARDS definition, ${ }^{4}$ which adopted chest imaging, origin of edema, oxygenation, and timing as critical parameters for ARDS identification. The definition required the following criteria:

- Imaging: A chest radiograph or computed tomography scan showing bilateral opacities not fully explained by effusions, lobar/lung collapse, or nodules.

- Origin of edema: Respiratory failure not fully explained by cardiac failure or fluid overload; objective assessment (e.g., echocardiography) needed to exclude hydrostatic edema if no risk factors present.

- Oxygenation: A ratio of partial pressure of arterial oxygen $\left(\mathrm{PaO}_{2}\right)$ divided by a fraction of inspired oxygen $\left(\mathrm{FiO}_{2}\right)$ $<300$. The severity of ARDS can subsequently be divided into mild $\left(\mathrm{PaO}_{2} / \mathrm{FiO}_{2}>200\right.$ to $\leq 300$ with positive end-expiratory pressure [PEEP] $\geq 5 \mathrm{~cm} \mathrm{H}_{2} \mathrm{O}$ ), moderate $\left(\mathrm{PaO}_{2} / \mathrm{FiO}_{2}>100\right.$ to $\leq 200$ with PEEP $\geq 5$ $\left.\mathrm{cm} \mathrm{H}_{2} \mathrm{O}\right)$, or severe $\left(\mathrm{PaO}_{2} / \mathrm{FiO}_{2} \leq 100\right.$ with PEEP $\geq 5$ $\mathrm{cm} \mathrm{H}_{2} \mathrm{O}$ ).

- Timing: Occurring within 1 week of a known clinical insult or new or worsening respiratory symptoms.

Notably, ARDS categories of mild, moderate, and severe correlate with mortality rates of $27 \%, 32 \%$, and $45 \%$, respectively, bringing objectivity to everyday practice. ${ }^{4}$ Furthermore, mortality rates have shown variation depending on the underlying cause of ARDS. For example, severe sepsis due to a pulmonary source of infection presented an overall mortality of $40.6 \%$, while ARDS due to severe trauma (injury severity score $>15$ ) had a mortality of $24.1 \% .^{2}$

\section{CAUSES AND RISK FACTORS}

Numerous conditions may cause ARDS (Table 1), with sepsis being the most common, accounting for $46 \%$ of cases. $^{2}$ Among risk factors, patient-related variables have been found to be associated with an increased incidence and mortality in ARDS, such as age, ${ }^{2,5-7}$ African American race, ${ }^{8}$ male gender, alcoholism, ${ }^{9-11}$ and smoking. ${ }^{12,13}$ The presence of obesity has been linked to an increased incidence of ARDS, but its effect on mortality is unclear. ${ }^{14,15}$

The ability to predict which admitted patients experience ARDS complications has been an area of growing interest and research. In fact, tools have been described and further validated. Specifically, the Lung Injury Prediction Score (LIPS) (Table 2) is a calculative tool that used a prospective cohort of 5584 admitted patients and their associated risk factors. ${ }^{16}$ Interestingly, a LIPS score of 4 or higher was associated with increased risk of ARDS development within a median of 2 days. Notably, the score has a sensitivity of $69 \%$ and a specificity of $78 \%$, with a positive predictive value of $18 \%$ and a negative predictive value of $97 \%$.

\section{PATHOPHYSIOLOGY OF ARDS AND VENTILATOR-INDUCED LUNG INJURY}

The primary function of a normal healthy lung is to facilitate gas exchange with oxygen and carbon dioxide via the alveoli. Following a direct or indirect insult, patients may progress through three pathologic phases of ARDS.

First, the exudative phase consists of activation of alveolar macrophages, release of proinflammatory cytokines, complement activation, and immune cell recruitment. Overall, this results in alveolar damage, allowing protein-rich fluid to flood the alveoli. In addition to irreversible damage of type I alveolar cells, type II cells sustain injury and impair the production of surfactant.

Second, the proliferative phase occurs when the patient's endogenous anti-inflammatory system begins to clear the localized inflammatory response. It is therefore essential for host survival. During this phase, type II cells proliferate, leading to restoration of the epithelial barrier and surfactant production.

Finally, the fibrotic phase occurs based on the extent of damage during the exudative phase. Not every patient experiences this phase, and the mechanisms are not completely understood; however, it is thought to be related to overproliferation of fibroblasts. Clinically, patients develop reduced lung elasticity and increased physiological dead space. Due to the natural course of the disease state, it is important to minimize additional sources of lung injuries, particularly ventilator-induced lung injury.

In a normal healthy lung, fluid movement is regulated to keep the alveoli dry and hold on to a small amount of interstitial fluid. Lung injury, such as ARDS, disrupts this 
Table 2. Lung Injury Prediction Score calculation worksheet

\begin{tabular}{|c|c|c|}
\hline Category & Variable & Points \\
\hline \multirow{15}{*}{$\begin{array}{l}\text { Predisposing } \\
\text { conditions }\end{array}$} & Shock & 2 \\
\hline & Aspiration & 2 \\
\hline & Sepsis & 1 \\
\hline & Pneumonia & 1.5 \\
\hline & High-risk surgery ${ }^{a}$ & \\
\hline & Orthopedic spine & 1 \\
\hline & Acute abdomen & 2 \\
\hline & Cardiac & 2.5 \\
\hline & Aortic vascular & 3.5 \\
\hline & High-risk trauma & \\
\hline & Traumatic brain injury & 2 \\
\hline & Smoke inhalation & 2 \\
\hline & Near drowning & 2 \\
\hline & Lung contusion & 1.5 \\
\hline & Multiple fractures & 1.5 \\
\hline \multirow[t]{9}{*}{ Risk modifiers } & Alcohol abuse & 1 \\
\hline & $\begin{array}{l}\text { Obesity (body mass index } \\
>30 \mathrm{~kg} / \mathrm{m}^{2} \text { ) }\end{array}$ & 1 \\
\hline & Hypoalbuminemia & 1 \\
\hline & Chemotherapy & 1 \\
\hline & $\begin{array}{l}\text { Fraction of inspired oxygen } \\
\quad>0.35(>4 \mathrm{~L} / \mathrm{min})\end{array}$ & 2 \\
\hline & Tachypnea (respiratory rate $>30 / \mathrm{min}$ ) & 1.5 \\
\hline & Oxygen saturation $<95 \%$ & 1 \\
\hline & Acidosis (pH <7.35) & 1.5 \\
\hline & Diabetes mellitus ${ }^{b}$ & -1 \\
\hline
\end{tabular}

${ }^{a}$ Add 1.5 points if emergency surgery.

${ }^{b}$ Only if sepsis.

Reprinted from Gajic et al (2011) $)^{33}$ with permission of the American Thoracic Society. Copyright () American Thoracic Society. The American Journal of Respiratory and Critical Care Medicine is an official journal of the American Thoracic Society.

regulatory process, resulting in diffuse alveolar damage. ${ }^{17}$ One form of ventilator-induced injury, referred to as "biotrauma," can happen in both healthy and injured lungs. ${ }^{18}$ It causes a systemic inflammatory response releasing a cascade of cytokines. ${ }^{18}$ Three general regions of the lung have been described in ARDS: normal lung tissue, densely consolidated lung, and a collapsible region during expiration that is recruitable during inspiration. ${ }^{19}$ In the absence of optimal PEEP, this collapsible/recruitable region of the lung can form an injury known as "atelectrauma" due to the repeated opening and closing of the airway and alveoli. ${ }^{20}$ Proposed methods to determine optimal PEEP will be discussed further.

\section{STANDARD TREATMENT \\ Noninvasive strategy}

High-flow nasal cannula (HFNC) and noninvasive positive-pressure ventilation (NIPPV) devices have been used as step-up therapy for hypoxemic patients when standard oxygen delivery devices fail. The FLORALI trial was a multicenter open-label trial of patients with a $\mathrm{PaO}_{2} / \mathrm{FiO}_{2}$ ratio $<300 \mathrm{~mm} \mathrm{Hg}$ comparing HFNC to NIPPV and standard oxygen therapy via face mask. There was no difference in the primary outcome of intubation rates by day 28 when looking at HFNC, NIPPV, or standard oxygen therapy $(38 \%$ vs $50 \%$ vs $47 \%$, respectively; $P=0.18) .{ }^{21}$ However, for the outcomes of intensive care unit (ICU) and 90-day mortality, HFNC had a statistically significant edge over the other two groups $(P=0.03$ and $P=0.01$, respectively), which is surprising given the nonsignificant rates of intubation. In a post hoc analysis of patients with a $\mathrm{PaO}_{2} / \mathrm{FiO}_{2}$ ratio of $\leq 200 \mathrm{~mm} \mathrm{Hg}$, the HFNC group had significantly lower rates of intubation $(P \leq 0.001)$. The lower rates of intubation of this group could be the driving cause of the reduced mortality, but since the data are derived from a post hoc analysis, further trials are needed.

\section{Low-tidal volume strategy}

Misuse of mechanical ventilation can cause lung injury with consequential poor outcomes. In ARDS, the role of mechanical ventilation is to provide both oxygenation and ventilation while minimizing further lung injury. The ARMA trial, designed by the ARDSnet investigators, was a multicenter prospective randomized controlled trial of 861 patients assigned to receive either low tidal volume ventilation $(6 \mathrm{~mL} / \mathrm{kg}$ of predicted body weight $)$ or conventional ventilation methods (12 mL/kg of predicted body weight). ${ }^{22}$ Tidal volumes were subsequently titrated to keep plateau pressures, defined as alveolar pressure at the end of a paused inspiration, $<30 \mathrm{~cm} \mathrm{H} \mathrm{H}_{2} \mathrm{O}$ in the intervention group and $<50 \mathrm{~cm} \mathrm{H} \mathrm{H}_{2} \mathrm{O}$ in the conventional arm. The results of the trial showed a reduction in mortality $(31 \%$ vs $39.8 \%, P=$ $0.007)$ and increased ventilator-free days (12 days vs 10 days, $P=0.007)$ in the low tidal volume group. This landmark study was supported by a meta-analysis of four randomized trials including 1149 patients showing a reduction in mortality while using a low tidal volume strategy $(34.2 \%$ vs $41 \%) .{ }^{23}$ Due to these findings, low tidal volume ventilation is considered standard of care in clinical practice.

ARDS recognition and subsequent early implementation of low tidal volume ventilation is important, with one study showing higher ICU mortality in patients in ARDS when low tidal volume was delayed. ${ }^{24}$ Of note, in certain cases, an ultra-low tidal volume lung protective strategy $(4 \mathrm{~mL} / \mathrm{kg}$ of predicted body weight) may be needed to bring the plateau pressure down to $<30 \mathrm{~cm} \mathrm{H}_{2} \mathrm{O}^{25}$ Nevertheless, careful monitoring and treatment of severe acid-base disarrangements may be required. 


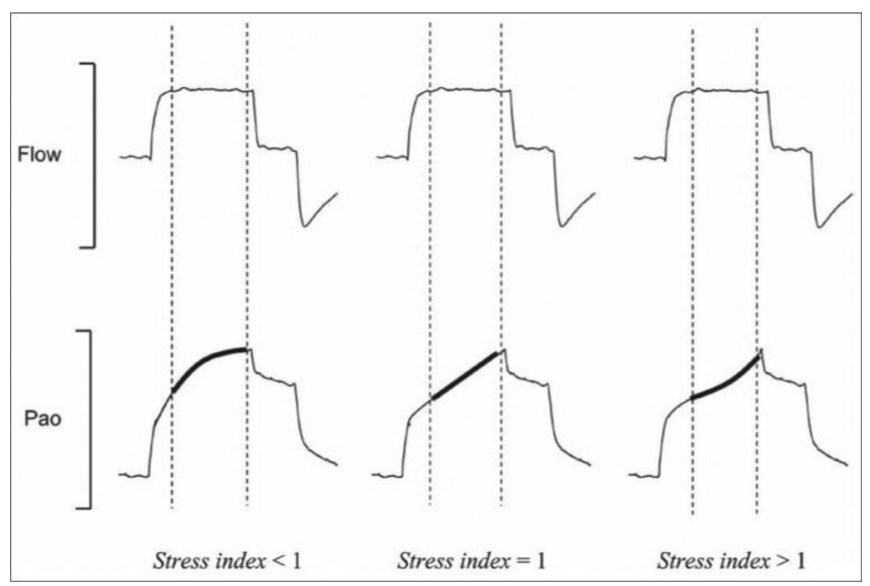

Figure 1. Graphic representation of the stress index concept. Pao indicates airway pressure. During constant flow, there is volume-cycled mechanical ventilation. For stress index values $<1$, the Pao curve presents a downward concavity, suggesting a continuous decrease in elastance during constantflow inflation. For stress index values $>1$, the curve presents an upward concavity, suggesting a continuous increase in elastance. Finally, for a stress index value equal to 1, the curve is straight, suggesting the absence of tidal variations in elastance. Reprinted with permission from Proc (Bayl Univ Med Cent). 2015;28(2):163-171.

\section{Positive end-expiratory pressure}

PEEP recruits collapsed alveoli by reducing atelectasis and prevents the impact of cyclic opening and closing of alveoli, which may trigger an abrupt release of cytokines with a consequent systemic inflammatory response syndrome. The optimal level of PEEP has been a matter of controversy. Therefore, it is imperative that individual ventilator parameters (i.e., static respiratory system compliance, tidal volume, and plateau pressure) are considered before deciding on a particular PEEP setting. One proposed way to select PEEP is by optimizing driving pressure $(\Delta \mathrm{P})$. Driving pressure is defined as tidal volume divided by static respiratory system compliance. It can be easily calculated at the bedside by subtracting PEEP from plateau pressure $(\Delta \mathrm{P}=$ plateau pressure - PEEP). A 2015 meta-analysis of 3562 patients with ARDS, which included nine trials, showed that decreasing driving pressure to levels $<15 \mathrm{~cm} \mathrm{H}_{2} \mathrm{O}$ was associated with increased survival. A larger systemic review and meta-analysis including 6062 patients supported this finding. ${ }^{26,27}$

Another proposed method to select PEEP is the analysis of the pressure-time curve by calculating the stress index. ${ }^{28}$ To assess the stress index, the ventilator must be set on volume control mode, with flow on a square waveform. Under these circumstances, the assessment of the slope of the airway pressure-time waveform allows a qualitative analysis of stress index (Figure 1). A value $<1$ suggests a potentially recruitable lung and a decrease in elastance during inspiration. Therefore, PEEP can be increased. Values $>1$ are consistent with hyperinflation and an increase in lung elastance during inspiration. Hence, PEEP level should be decreased. Finally, a flat slope (stress index $=1$ ) indicates an optimal PEEP level. Although this method is physiologically interesting, more trials are needed to validate it.

The EXPRESS trial was a multicenter randomized controlled trial of 767 patients in 37 French ICUs. ${ }^{29}$ This trial randomized patients to a low PEEP $\left(5-9 \mathrm{~cm} \mathrm{H}_{2} \mathrm{O}\right)$ or "minimal distention" group or to a "maximal recruitment" group, where PEEP levels were increased to reach a maximum plateau pressure of 28 to $30 \mathrm{~cm} \mathrm{H}_{2} \mathrm{O}$. This trial showed no mortality benefit with either strategy. However, in a subgroup of patients with refractory hypoxemia, the "maximal recruitment" group showed better oxygenation, lung compliance, ventilator-free days (7 vs 3 days; $P=$ 0.04 ), and organ failure-free days (6 vs 2 days; $P=0.04$ ).

The recent ART study was a multicenter randomized trial, which included 1010 patients to assess whether lung recruitment maneuvers plus PEEP titration would improve clinical outcomes in moderate to severe ARDS. ${ }^{30}$ The experimental group included lung recruitment maneuvers and PEEP titration according to respiratory system compliance evaluations, whereas the control group used a low PEEP strategy (based on the ARDSnet protocol). The experimental group allowed temporary PEEP titrations up to $45 \mathrm{~cm} \mathrm{H}_{2} \mathrm{O}$, maintaining a maximal driving pressure at $15 \mathrm{~cm} \mathrm{H}_{2} \mathrm{O}$. Then, after a recruitment maneuver, PEEP was titrated down to a minimum of $11 \mathrm{~cm} \mathrm{H}_{2} \mathrm{O}$. This study revealed that the experimental group had a significantly higher 28day mortality compared with the control group $(55.3 \%$ vs $49.3 \% ; P=0.04)$, as well as an increased risk of pneumothorax requiring intervention $(3.2 \%$ vs $1.2 \% ; P=0.03)$ and increased risk of barotrauma (5.6\% vs $1.6 \% ; P=0.001)$. Despite these findings, there were no differences in ICU mortality, in-hospital mortality, or length of stay.

Lastly, the 2019 trial EPVent 2, following the positive results of the EPVent study, was a multicenter randomized controlled trial of 200 patients that examined the use of esophageal manometry using an esophageal balloon as a surrogate for pleural pressure to titrate PEEP compared with a control group of empiric high PEEP (based on a table from the OSCILLATE trial). ${ }^{31}$ In the esophageal balloon group, PEEP was titrated to keep end expiratory pleural pressures (estimated by use of the balloon) between 0 and $6 \mathrm{~cm} \mathrm{H}_{2} \mathrm{O}$ to keep the PEEP near the pleural pressure. Upon analysis, no difference was found in 28-day, 60-day, or 1-year mortality in the esophageal balloon group vs placebo, nor any difference in ventilator-free days or ICU length of stay. ${ }^{31}$ These results point away from the routine use of esophageal manometry in ARDS. There are also deleterious effects of too much PEEP, including reduced venous return and reduced cardiac output due to increased intrathoracic pressure, thus causing negative hemodynamic effects, as well as hyperinflation leading to lung injury. ${ }^{32}$

In summary, the optimal level of PEEP is still unknown. Nevertheless, previously described strategies based on physiologic parameters may provide guidance to practicing providers. 


\section{Prone positioning}

Prone positioning has proven to be beneficial in severe ARDS by improving oxygenation and survival. ${ }^{33}$ Physiologically, prone positioning can decrease ventilationperfusion mismatch by improving uniformity of ventilation distribution. Despite its benefits, prone positioning may bring about serious complications, if not monitored carefully, such as hardware displacement and pressure ulcers. While earlier clinical studies did not show an impact on survival, ${ }^{34-40}$ the PROSEVA study did. ${ }^{33}$ This study was a multicenter prospective randomized control trial that included 466 patients with severe ARDS $\left(\mathrm{PaO}_{2} / \mathrm{FiO}_{2}<150\right.$, on $\mathrm{FiO}_{2}$ $\geq 0.6$ and PEEP $\geq 5 \mathrm{~cm} \mathrm{H}_{2} \mathrm{O}$ ), who were in prone positioning for at least $16 \mathrm{~h}$. The control group remained supine. The intervention group presented a decreased 28-day mortality $(16 \%$ vs $33 \% ; P \leq 0.001)$ and 90 -day mortality $(24 \%$ vs $41 \% ; P \leq 0.001)$. Furthermore, there was an increase in ventilator-free days (14 vs 10 days at day $28, P \leq 0.001$ ). Importantly, there was no significant difference in the incidence of complications between the two groups. Despite the aforementioned positive findings, it is important to recognize that absolute and relative contraindications for prone positioning exist, such as elevated intracranial pressure, hemodynamic and cardiac abnormalities, spinal instability, recent thoracic and abdominal surgeries, massive hemoptysis, and anterior chest tubes with active leaks.

\section{Neuromuscular blocking agents}

Although low tidal volume remains the first-line treatment for patients with ARDS, these patients are still at risk of developing ventilator-induced lung injury. Neuromuscular blockade (NMB) has been suggested as a way to reduce the risk of these adverse events by decreasing patient-ventilator dyssynchrony. ${ }^{41}$ Furthermore, it has been suggested that some NMB may have direct anti-inflammatory effects, providing some benefits in ARDS patients. ${ }^{42}$ The ACURASYS trial enrolled 340 patients within the first $48 \mathrm{~h}$ of ARDS diagnosis to receive cisatracurium vs placebo, in addition to standard ARDS management. ${ }^{43}$ Every patient received sedation to a Ramsay sedation score of 6 . Upon analysis, cisatracurium showed a decreased mortality at 28 days $(23.7 \%$ vs $33.3 \% ; P=0.05)$ and a lower adjusted 90 -day mortality (31.6\% vs $40.7 \% ; P=0.08)$. NMB was also associated with significant reductions of barotrauma, pneumothorax, length of stay in the ICU, and days on the ventilator. Despite these results, due to concerns of post-ICU syndrome, ICUacquired posttraumatic stress disorder, and prolonged ICUacquired weakness, the routine use of NMB has not been widely adopted.

In 2019, the ROSE trial investigated the use of NMB in ARDS patients. While the intervention group received significant sedation, the control group received light sedation. ${ }^{44}$ Otherwise, this trial was modeled after the ACURASYS trial. Upon analysis, the study did not show any difference in $90-$ day in-hospital mortality (42\% cisatracurium vs $43 \%$ control; $P=0.93)$. Nor did it show any difference in 28-day mortality, barotrauma, or ICU length of stay. This study has drawn some criticism, as $17 \%$ of patients in the control arm ended up receiving $\mathrm{NMB}$, and a large number of patients were excluded from the trial due to NMB already being utilized. In summary, NMB may provide benefits in ARDS patients who require deep sedation.

\section{Hemodynamic monitoring and fluid management}

Avoidance of fluid accumulation, especially in the thorax, is considered beneficial in critically ill patients. The FACTT trial evaluated fluid management in ARDS by using a strict fluid balance protocol guided by central line or pulmonary artery catheter data. ${ }^{45}$ The study included 1000 patients, randomized to one of four hemodynamic protocols for a week. The conservative fluid group aimed at a pulmonary artery occlusion pressure of $<8 \mathrm{~mm} \mathrm{Hg}$ or a central venous pressure of $<4 \mathrm{~mm} \mathrm{Hg}$, whereas the liberal fluid group aimed at a central venous pressure of 10 to $14 \mathrm{~mm} \mathrm{Hg}$ or a pulmonary artery occlusion pressure of 14 to $18 \mathrm{~mm} \mathrm{Hg}$. Upon analysis, the liberal fluid group presented a net positive fluid balance of $6992 \pm 502 \mathrm{~mL}$, while the conservative fluid group ended up with a negative fluid balance of $136 \pm 491$ $\mathrm{mm} \mathrm{Hg}(P \leq 0.001)$. Importantly, the conservative use of fluid was not associated with an increased need for dialysis or an incidence of shock in the first 60 days $(19 \%$ vs $14 \% ; P=$ $0.06)$. Also, a conservative fluid strategy showed an increase in ventilator-free days $(14.6 \pm 0.5$ vs $12.1 \pm 0.5 ; P \leq 0.001)$. This pivotal trial remains the best supporting evidence for a conservative fluid strategy when managing patients with ARDS.

\section{TREATMENT IN REFRACTORY HYPOXEMIA}

In certain ARDS patients, conventional therapies may fail to improve oxygenation. Hence, other "salvage therapies" have been proposed, aiming at improving clinical outcomes.

\section{Extracorporeal membrane oxygenation}

ARDS patients with severe refractory hypoxemia, excessively high plateau pressures, and/or severe hypercapnic acidosis ( $\mathrm{pH}<7.15)$, despite standard-of-care treatment, may benefit from extracorporeal membrane oxygenation (ECMO). ${ }^{46-49}$ Despite prior negative trials, ${ }^{50}$ the Conventional Ventilator Support vs ECMO for Severe Adult Respiratory Failure (CESAR) trial looked at 180 patients with refractory ARDS in a prospective randomized study. ${ }^{46}$ Patients were randomized to receive veno-venous (VV) ECMO (after transfer to a specialized hospital) or standard conventional mechanical ventilation at regional medical centers. At the end of the study, the VV ECMO group had a higher 6-month survival than the conventional ventilation group (63\% vs $47 \%$; $P=0.03$ ).

Despite this positive result, the trial presents major shortcomings. First, patients in the intervention group received 
lung protective ventilation, whereas only $70 \%$ of the patients in the control group did. Second, only $75 \%$ of the patients in the intervention group received ECMO upon transfer to the specialized center. Hence, what the CESAR study ultimately showed was that patients with refractory ARDS had a survival benefit when transferred to a specialized center, rather than staying at their regional hospital.

Since a direct causality between use of VV ECMO and survival remained unclear, the EOLIA trial was conducted. This multicenter randomized controlled trial of 249 patients evaluated 60-day survival among a group of ARDS patients with early initiation of ECMO compared to standard care. ${ }^{47}$ Both groups were treated with low tidal volume ventilation, prone positioning, and $\mathrm{NMB}$ agents. In the end, VV ECMO did not show a reduction in 60-day mortality compared to standard care. However, crossover occurred in $28 \%$ of patients in the control group to the ECMO group, with $57 \%$ mortality among them.

\section{Corticosteroids}

Inflammation caused by cytokine release is an important component of ARDS. Thus, multiple studies have investigated the role of corticosteroids. Some trials focused on ARDS prevention in high-risk patients. ${ }^{48,49,51,52}$ However, study results have been less than promising. Specifically, Bone and colleagues showed an increased 14-day mortality utilizing steroids compared to the control group $(52 \%$ vs $22 \%){ }^{49}$ Similarly, Weigelt and colleagues showed an increased incidence of infection ( $77 \%$ vs $43 \%$ ) and ARDS $(64 \%$ vs $33 \%) .^{52}$ A few trials have examined glucocorticoid therapy in early and late ARDS stages. The first multicenter double-blinded prospective trial failed to demonstrate a statistically significant mortality benefit in patients given a short course of corticosteroids within the first $24 \mathrm{~h}$ of ARDS diagnosis. ${ }^{53}$ In 1998, Meduri and colleagues conducted a randomized placebo-controlled trial evaluating the effect of a prolonged course of methylprednisolone in patients with severe ARDS who failed to improve by day 7 of respiratory failure. This study showed a reduction in ICU mortality $(P$ $=0.02)$ and improved oxygenation $(P<0.001) .{ }^{54}$ In 2006 , Steinberg and colleagues randomly assigned 180 patients to methylprednisolone or placebo. Patients had moderate to severe ARDS and were eligible for enrollment 7 to 28 days after the onset of ARDS. Corticosteroids resulted in no difference in survival. Notably, mortality was increased among patients who received methylprednisolone after 14 days of ARDS onset. ${ }^{55}$ Shortly after, in 2007 Meduri and colleagues performed another randomized, placebo-controlled trial of 91 patients with ARDS evaluating an early and prolonged course of steroids vs placebo. ${ }^{56}$ This method showed a reduction in the duration of mechanical ventilation $(P=0.002)$, ICU stay $(P=0.007)$, and mortality $(20.6 \%$ vs $42.9 \% ; P=$ $0.03)$. The thought behind the contradictory findings of the prior studies and Meduri's trial from 2007 may be related to the timing of steroid initiation ( $>7$ days vs $72 \mathrm{~h}$ ) and the rapid taper of steroids in the former group. The most recent trial is DEXA-ARDS, a multicenter randomized controlled trial of 277 patients using intravenous dexamethasone $20 \mathrm{mg}$ for 5 days followed by $10 \mathrm{mg}$ for 5 days. ${ }^{57}$ The dexamethasone arm had an increased number of ventilator-free days compared to the routine care arm (12.3 vs $7.5 ; P \leq 0.0001)$, and all-cause mortality at 60 days was $21 \%$ vs $36 \%$, respectively $(P=0.005) .^{57}$

Data from clinical trials have not demonstrated consistent results to establish a definitive role for corticosteroids. However, there may be no role for corticosteroids in select populations. Most notably, Brun-Buisson and colleagues analyzed the impact of corticosteroid therapy in patients with ARDS associated with influenza $\mathrm{A} / \mathrm{H} 1 \mathrm{~N} 1$ pneumonia. Of the 208 patients included, $83(40 \%)$ received corticosteroids at an initial daily dose of hydrocortisone $270 \mathrm{mg}$ for a median of 11 days. Corticosteroids were associated with an increased mortality in both the unadjusted analysis $(P=$ $0.004)$ and propensity score-adjusted analysis $(P=0.002)$. Furthermore, a higher rate of acquired pneumonia $(P=$ $0.01)$ and fewer mechanical ventilator-free days $(P=0.01)$ were associated with corticosteroids. ${ }^{58}$ It is important to reiterate that the benefits of corticosteroids have only been demonstrated during the early phase of ARDS. Furthermore, initiation beyond 14 days of ARDS onset or with concomitant influenza pneumonia has been associated with increased mortality.

\section{Vasodilator therapy}

Selective inhaled pulmonary vasodilators recruit blood flow to ventilated lung segments with consequent improvement in oxygenation. ${ }^{59}$ Given the minimal systemic side effects and half-life of inhaled pulmonary vasodilators and their ability to improve oxygenation, they have been evaluated for use in ARDS. Two meta-analyses compared inhaled nitric oxide to placebo. Although a transient improvement in oxygenation occurred, there was no benefit in survival and ventilator-free days. ${ }^{60}$ Inhaled epoprostenol has also been evaluated in patients with ARDS, as it presents similar physiologic effects. Similarly, it also has not shown a mortality benefit.

\section{Nonconventional ventilation}

Nonconventional therapies such as high-frequency oscillatory ventilation and airway pressure release ventilation have been evaluated as methods of ventilation in patients with ARDS. High-frequency oscillatory ventilation employs very low tidal volumes (equal to or less than anatomic dead space) at frequencies of 3 to $15 \mathrm{~Hz}$. It has fallen out of use after two large studies failed to show a mortality benefit. ${ }^{61,62}$ In fact, one of those studies revealed a statistically significant increase in mortality with high-frequency oscillatory ventilation compared to conventional therapy.

Airway pressure release ventilation is a time-cycled, pressure-targeted ventilation mode that allows for spontaneous 
breathing across the entire breath cycle. It increases mean airway pressure without increasing peak pressure by employing long inspiratory times followed by very short expiratory times. Studies have shown that airway pressure release ventilation can improve alveolar recruitment, increase oxygenation, and decrease peak airway pressure. ${ }^{63-67}$ However, no trials to date have shown a mortality benefit when compared to conventional low tidal volume ventilation. Of note, given the allowance of spontaneous breaths, it has been shown that maintaining low tidal volumes $(<6.5 \mathrm{~mL} / \mathrm{kg})$ may not be feasible on a day-to-day basis during utilization of this mode of ventilation. $^{68}$

\section{CONCLUSION}

Despite numerous advances, ARDS is still associated with a high mortality. To date, only lung protective ventilation, prone positioning, and NMB have been shown to decrease mortality, while other ventilator strategies and adjuvant treatments may improve physiologic parameters. Further investigation is needed to overcome this prevalent and severe clinical condition.

\section{ORCID}

Christopher Wood (D) http://orcid.org/0000-0003-4503-2076

Vivek Kataria (D) http://orcid.org/0000-0003-1149-5937

1. Ashbaugh DG, Bigelow DB, Petty TL, Levine BE. Acute respiratory distress in adults. Lancet. 1967;290(7511):319-323. doi:10.1016/ S0140-6736(67)90168-7.

2. Rubenfeld GD, Caldwell E, Peabody E, et al. Incidence and outcomes of acute lung injury. N Engl J Med. 2005;353(16):1685-1693. doi:10. 1056/NEJMoa050333.

3. Bellani G, Laffey JG, Pham T, et al. Epidemiology, patterns of care, and mortality for patients with acute respiratory distress syndrome in intensive care units in 50 countries. JAMA. 2016;315(8):788-800. doi:10.1001/jama.2016.0291.

4. ARDS Definition Task Force, Ranieri VM, Rubenfeld GD, et al. Acute respiratory distress syndrome: the Berlin definition. JAMA. 2012;307(23):2526-2533. doi:10.1001/jama.2012.5669.

5. Suchyta MR, Clemmer TP, Elliott CG, et al. Increased mortality of older patients with acute respiratory distress syndrome. Chest. 1997; 111(5):1334-1339. doi:10.1378/chest.111.5.1334.

6. Ely EW, Wheeler AP, Thompson BT, Ancukiewicz M, Steinberg KP, Bernard GR. Recovery rate and prognosis in older persons who develop acute lung injury and the acute respiratory distress syndrome. Ann Intern Med. 2002;136(1):25-36. doi:10.7326/0003-4819-136-1200201010-00007.

7. Eachempati SR, Hydo LJ, Shou J, Barie PS. Outcomes of acute respiratory distress syndrome (ARDS) in elderly patients. J Trauma. 2007;63(2):344-350.

8. Moss M, Mannino DM. Race and gender differences in acute respiratory distress syndrome deaths in the United States: an analysis of multiple-cause mortality data (1979-1996). Crit Care Med. 2002;30(8): 1679-1685. doi:10.1097/00003246-200208000-00001.

9. Moss M, Bucher B, Moore FA, Moore EE, Parsons PE. The role of chronic alcohol abuse in the development of acute respiratory distress syndrome in adults. JAMA. 1996;275(1):50-54. doi:10.1001/jama. 1996.03530250054027 .
10. Moss M, Parsons PE, Steinberg KP, et al. Chronic alcohol abuse is associated with an increased incidence of acute respiratory distress syndrome and severity of multiple organ dysfunction in patients with septic shock. Crit Care Med. 2003;31(3):869-877.

11. Iscimen R, Cartin-Ceba R, Yilmaz M, et al. Risk factors for the development of acute lung injury in patients with septic shock: an observational cohort study. Crit Care Med. 2008;36(5):1518-1522.

12. Iribarren C, Jacobs DR Jr, Sidney S, Gross MD, Eisner MD. Cigarette smoking, alcohol consumption, and risk of ARDS: a 15-year cohort study in a managed care setting. Chest. 2000;117(1):163-168. doi:10.1378/chest.117.1.163.

13. Calfee CS, Matthay MA, Eisner MD, et al. Active and passive cigarette smoking and acute lung injury after severe blunt trauma. Am J Respir Crit Care Med. 2011;183(12):1660-1665. doi:10.1164/rccm. 201011-1802OC.

14. Gong MN, Bajwa EK, Thompson BT, Christiani DC. Body mass index is associated with the development of acute respiratory distress syndrome. Thorax. 2010;65(1):44-50. doi:10.1136/thx.2009.117572.

15. Anzueto A, Frutos-Vivar F, Esteban A, et al. Influence of body mass index on outcome of the mechanically ventilated patients. Thorax. 2011;66(1):66-73. doi:10.1136/thx.2010.145086.

16. Gajic O, Dabbagh O, Park PK, et al. Early identification of patients at risk of acute lung injury: evaluation of lung injury prediction score in a multicenter cohort study. Am J Respir Crit Care Med. 2011; 183(4):462-470. doi:10.1164/rccm.201004-0549OC.

17. Piantadosi CA, Schwartz DA. The acute respiratory distress syndrome. Ann Intern Med. 2004;141(6):460. doi:10.7326/0003-4819-141-6200409210-00012.

18. Halbertsma FJ, Vaneker M, Scheffer GJ, van der Hoeven JG. Cytokines and biotrauma in ventilator-induced lung injury: a critical review of the literature. Neth J Med. 2005;63(10):382-392.

19. Gattinoni L, Caironi P, Pelosi P, Goodman LR. What has computed tomography taught us about the acute respiratory distress syndrome? Am J Respir Crit Care Med. 2001;164(9):1701-1711. doi:10.1164/ ajrccm.164.9.2103121.

20. Slutsky AS. Lung injury caused by mechanical ventilation. Chest. 1999;116(1 Suppl):9S-15S. doi:10.1378/chest.116.suppl_1.9S-a.

21. Frat J, Thille A, Mercat A, et al. High-flow oxygen through nasal cannula in acute hypoxemic respiratory failure. $N$ Engl J Med. 2015; 372(23):2185-2196. doi:10.1056/NEJMoa1503326.

22. The Acute Respiratory Distress Syndrome Network. Ventilation with lower tidal volumes as compared with traditional tidal volumes for acute lung injury and the acute respiratory distress syndrome. $N$ Engl J Med. 2000;342(18):1301-1308.

23. Putensen C, Theuerkauf N, Zinserling J, Wriggle H, Pelosi P. Metaanalysis: ventilation strategies and outcomes of the acute respiratory distress syndrome and acute lung injury. Ann Intern Med. 2009; 151(8):566-576. doi:10.7326/0003-4819-151-8-200910200-00011.

24. Needham DM, Yang T, Dinglas VD, et al. Timing of low tidal volume ventilation and intensive care unit mortality in acute respiratory distress syndrome. A prospective cohort study. Am J Respir Crit Care Med. 2015;191(2):177-185. doi:10.1164/rccm.201409-1598OC.

25. Richard JC, Marque S, Gros A, et al. Feasibility and safety of ultralow tidal volume ventilation without extracorporeal circulation in moderately severe and severe ARDS patients. Intensive Care Med. 2019;45(11):1590-1598. doi:10.1007/s00134-019-05776-x.

26. Amato MB, Meade MO, Slutsky AS, et al. Driving pressure and survival in the acute respiratory distress syndrome. N Engl J Med. 2015; 372(8):747-755. doi:10.1056/NEJMsa1410639.

27. Aoyama H, Pettenuzzo T, Aoyama K, Pinto R, Englesakis M, Fan E. Association of driving pressure with mortality among ventilated patients with acute respiratory distress syndrome: a systematic review and meta-analysis. Crit Care Med. 2018;46(2):300-306. doi:10.1097/ CCM.0000000000002838.

28. Grasso S, Stripoli T, De Michele M, et al. ARDSnet ventilatory protocol and alveolar hyperinflation: role of positive end-expiratory 
pressure. Am J Respir Crit Care Med. 2007;176(8):761-767. doi:10. 1164/rccm.200702-193OC.

29. Mercat A, Richard JC, Vielle B, et al. Positive end-expiratory pressure setting in adults with acute lung injury and acute respiratory distress syndrome: a randomized controlled trial. JAMA. 2008;299(6): 646-655. doi:10.1001/jama.299.6.646.

30. Cavalcanti AB, Suzumura A, Laranjeira LN, et al. Effect of lung recruitment and titrated positive end-expiratory pressure (PEEP) vs low PEEP on mortality in patients with acute respiratory distress syndrome. JAMA. 2017; 318(14):1335-1345. doi:10.1001/jama.2017. 14171.

31. Beitler JR, Sarge T, Banner-Goodspeed VM, et al. Effect of titrating positive end-expiratory pressure (PEEP) with an esophageal pressure-guided strategy vs an empirical high $\mathrm{PEEP}-\mathrm{FiO}_{2}$ strategy on death and days free from mechanical ventilation among patients with acute respiratory distress syndrome: a randomized clinical trial. JAMA. 2019;321(9):846-857. doi:10.1001/jama.2019.0555.

32. Luecke T, Pelosi P. Clinical review: positive end-expiratory pressure and cardiac output. Crit Care. 2005;9(6):607-621. doi:10.1186/ cc3877.

33. Guérin C, Reignier J, Richard J-C, et al. Prone positioning in severe acute respiratory distress syndrome. $N$ Engl J Med. 2013;368(23): 2159-2168. doi:10.1056/NEJMoa1214103.

34. Pelosi P, Tubiolo D, Mascheroni D, et al. Effects of the prone position on respiratory mechanics and gas exchange during acute lung injury. Am J Respir Crit Care Med. 1998;157(2):387-393. doi:10. 1164/ajrccm.157.2.97-04023.

35. Mure M, Martling CR, Lindahl SG. Dramatic effect on oxygenation in patients with severe acute lung insufficiency treated in the prone position. Crit Care Med. 1997;25(9):1539-1544.

36. Blanch L, Mancebo J, Perez M, et al. Short-term effects of prone position in critically ill patients with acute respiratory distress syndrome. Intensive Care Med. 1997;23(10):1033-1039. doi:10.1007/s001340050453.

37. Gattinoni L, Tognoni G, Pesenti A, et al. Effect of prone positioning on the survival of patients with acute respiratory failure. $N$ Engl J Med. 2001;345(8):568-573. doi:10.1056/NEJMoa010043.

38. Guerin C, Gaillard S, Lemasson S, et al. Effects of systematic prone positioning in hypoxemic acute respiratory failure: randomized controlled trial. JAMA. 2004;292(19):2379-2387. doi:10.1001/jama.292. 19.2379 .

39. Taccone P, Pesenti A, Latini R, et al. Prone positioning in patients with moderate and severe acute respiratory distress syndrome: a randomized controlled trial. JAMA. 2009;302(18):1977-1984. doi:10. 1001/jama.2009.1614.

40. Mancebo J, Fernandez R, Blanch L, et al. A multicenter trial of prolonged prone ventilation in severe acute respiratory distress syndrome. Am J Respir Crit Care Med. 2006;173(11):1233-1239. doi:10.1164/ rccm.200503-353OC.

41. Vender JS, Szokol JW, Murphy GS, Nitsun M. Sedation, analgesia, and neuromuscular blockade in sepsis: an evidence-based review. Crit Care Med. 2004;32(11 Suppl):S554-S561. doi:10.1097/01.ccm. 0000145907.86298.12.

42. Fanelli V, Morita Y, Cappello P, et al. Neuromuscular blocking agent cisatracurium attenuates lung injury by inhibition of nicotinic acetylcholine receptor- $\alpha 1$. Anesthesiology. 2016;124:132-140.

43. Papazian L, Forel JM, Gacouin A, et al. Neuromuscular blockers in early acute respiratory distress syndrome. $N$ Engl J Med. 2010; 363(12):1107-1116. doi:10.1056/NEJMoa1005372.

44. National Heart, Lung, and Blood Institute PETAL Clinical Trials Network. Early neuromuscular blockade in the acute respiratory distress syndrome. N Engl J Med. 2019;380(21):1997-2008.

45. National Heart, Lung, and Blood Institute Acute Respiratory Distress Syndrome (ARDS) Clinical Trials Network, Wiedemann HP, Wheeler AP, et al. Comparison of two fluid-management strategies in acute lung injury. N Engl J Med. 2006;354(24):2564-2575.
46. Peek GJ, Mugford M, Tiruvoipati R, et al. Efficacy and economic assessment of conventional ventilatory support versus extracorporeal membrane oxygenation for severe adult respiratory failure (CESAR): a multicentre randomised controlled trial. Lancet. 2009;374(9698): 1351-1363. doi:10.1016/S0140-6736(09)61069-2.

47. Combes A, Hajage D, Capellier G, et al. Extracorporeal membrane oxygenation for severe acute respiratory distress syndrome. $N$ Engl J Med. 2018;378(21):1965-1975. doi:10.1056/NEJMoa1800385.

48. Schein RM, Bergman R, Marcial EH, et al. Complement activation and corticosteroid therapy in the development of the adult respiratory distress syndrome. Chest. 1987;91(6):850-854. doi:10.1378/chest.91. 6.850 .

49. Bone RC, Fisher CJ, Jr, Clemmer TP, Slotman GJ, Metz CA. Early methylprednisolone treatment for septic syndrome and the adult respiratory distress syndrome. Chest. 1987;92(6):1032-1036. doi:10. 1378/chest.92.6.1032.

50. Zapol WM, Snider MT, Hill JD, et al. Extracorporeal membrane oxygenation in severe acute respiratory failure: a randomized prospective study. JAMA. 1979;242(20):2193-2196. doi:10.1001/jama.1979. 03300200023016.

51. Luce JM, Montgomery AB, Marks JD, Turner J, Metz CA, Murray JF. Ineffectiveness of high-dose methylprednisolone in preventing parenchymal lung injury and improving mortality in patients with septic shock. Am Rev Respir Dis. 1988;138(1):62-68. doi:10.1164/ajrccm/ 138.1.62.

52. Weigelt JA, Norcross JF, Borman KR, Snyder WH 3rd. Early steroid therapy for respiratory failure. Arch Surg. 1985;120(5):536-540. doi: 10.1001/archsurg.1985.01390290018003.

53. Bernard GR, Luce JM, Sprung CL, et al. High-dose corticosteroids in patients with the adult respiratory distress syndrome. $N$ Engl J Med. 1987;317(25):1565-1570. doi:10.1056/NEJM198712173172504.

54. Meduri GU, Headley AS, Golden E, et al. Effect of prolonged methylprednisolone therapy in unresolving acute respiratory distress syndrome: a randomized controlled trial. JAMA. 1998;280(2):159-165. doi:10.1001/jama.280.2.159.

55. Steinberg KP, Hudson LD, Goodman RB, et al. Efficacy and safety of corticosteroids for persistent acute respiratory distress syndrome. $N$ Engl J Med. 2006;354(16):1671-1684. doi:10.1056/NEJMoa051693.

56. Meduri GU, Golden E, Freire AX, et al. Methylprednisolone infusion in early severe ARDS: results of a randomized controlled trial. Chest. 2007;131(4):954-963. doi:10.1378/chest.06-2100.

57. Villar J, Ferrando C, Martínez D, et al. Dexamethasone treatment for the acute respiratory distress syndrome: a multicentre, randomised controlled trial. Lancet Respir Med. 2020;8(3):267-276. doi:10.1016/ S2213-2600(19)30417-5.

58. Brun-Buisson C, Richard J, Mercat A, et al. Early corticosteroids in severe influenza $\mathrm{A} / \mathrm{H} 1 \mathrm{~N} 1$ pneumonia and acute respiratory distress syndrome. Am J Respir Crit Care Med. 2011;183(9):1200-1206. doi: 10.1164/rccm.201101-0135OC.

59. Rossaint R, Falke KJ, Lopez F, Slama K, Pison U, Zapol WM. Inhaled nitric oxide for the adult respiratory distress syndrome. $N$ Engl J Med. 1993;328(6):399-405. doi:10.1056/NEJM199302113280605.

60. Adhikari NK, Burns KE, Friedrich JO, Granton JT, Cook DJ, Meade MO. Effect of nitric oxide on oxygenation and mortality in acute lung injury: systematic review and meta-analysis. BMJ. 2007; 334(7597):779. doi:10.1136/bmj.39139.716794.55.

61. Ferguson ND, Cook DJ, Guyatt GH, et al. High-frequency oscillation in early acute respiratory distress syndrome. N Engl J Med. 2013; 368(9):795-805. doi:10.1056/NEJMoa1215554.

62. Young D, Lamb SE, Shah S, et al. High-frequency oscillation for acute respiratory distress syndrome. N Engl J Med. 2013;368(9): 806-813. doi:10.1056/NEJMoa1215716.

63. Putensen C, Mutz NJ, Putensen-Himmer G, Zinserling J. Spontaneous breathing during ventilatory support improves ventilation-perfusion distributions in patients with acute respiratory distress 
syndrome. Am J Respir Crit Care Med. 1999;159(4):1241-1248. doi: 10.1164/ajrccm.159.4.9806077.

64. Neumann P, Golisch W, Strohmeyer A, Buscher H, Burchardi H, Sydow M. Influence of different release times on spontaneous breathing pattern during airway pressure release ventilation. Intensive Care Med. 2002;28(12):1742-1749. doi:10.1007/s00134002-1522-0.

65. Bugedo G, Bruhn A, Hernandez G, et al. Lung computed tomography during a lung recruitment maneuver in patients with acute lung injury. Intensive Care Med. 2003;29(2):218-225. doi:10.1007/ s00134-002-1618-6.
66. Rasanen J, Cane RD, Downs JB, et al. Airway pressure release ventilation during acute lung injury: a prospective multicenter trial. Crit Care Med. 1991;19(10):1234-1241. doi:10.1097/00003246-199110000-00004.

67. Valente Barbas CS. Lung recruitment maneuvers in acute respiratory distress syndrome and facilitating resolution. Crit Care Med. 2003; 31(4 Suppl):S265-S271.

68. Hirshberg EL, Lanspa MJ, Peterson J, et al. Randomized feasibility trial of a low tidal volume-airway pressure release ventilation protocol compared with traditional airway pressure release ventilation and volume control ventilation protocols. Crit Care Med. 2018;46(12): 1943-1952. doi:10.1097/CCM.0000000000003437. 